IFAS Extension

\title{
Datos sobre los minerales ${ }^{1}$
}

\author{
R. Elaine Turner y Wendy J. Dahl ${ }^{2}$
}

\section{¿Qué son los minerales?}

Si la palabra "mineral" hace que piense en rocas, ¡está en lo correcto! Los minerales son substancias como el calcio, el fósforo, el hierro y el zinc que se encuentran en las rocas y la tierra. También, se necesitan para tener una nutrición adecuada. Hay 16 minerales diferentes que sabemos que son necesarios en nuestra dieta. Varios otros minerales pueden ser necesarios en cantidades pequeñas.

\section{¿Cuáles son los diferentes tipos de minerales?}

Los minerales están agrupados como macrominerales y trazas de minerales. Los macrominerales son los que se encuentran en grandes cantidades en el cuerpo y se necesitan en grandes cantidades en la dieta. El calcio y el fósforo son dos de los siete macrominerales que necesitamos en nuestras dietas.

Las trazas de minerales se encuentran en pequeñas cantidades en el cuerpo y se necesitan en cantidades pequeñas en la dieta. Necesitamos incluir nueve trazas de minerales en nuestra dieta, incluyendo hierro y zinc.
Tabla 1. Los 16 minerales que necesitamos en nuestra dieta

\begin{tabular}{|c|c|}
\hline Macrominerales & Minerales traza \\
\hline Sodio & Hierro \\
\hline Potasio & Zinc \\
\hline Cloruro & Yoduro \\
\hline Calcio & Selenio \\
\hline Fósforo & Cobre \\
\hline Magnesio & Flúor \\
\hline Azufre & Cromo \\
\hline & Molibdeno \\
\hline & Manganeso \\
\hline
\end{tabular}

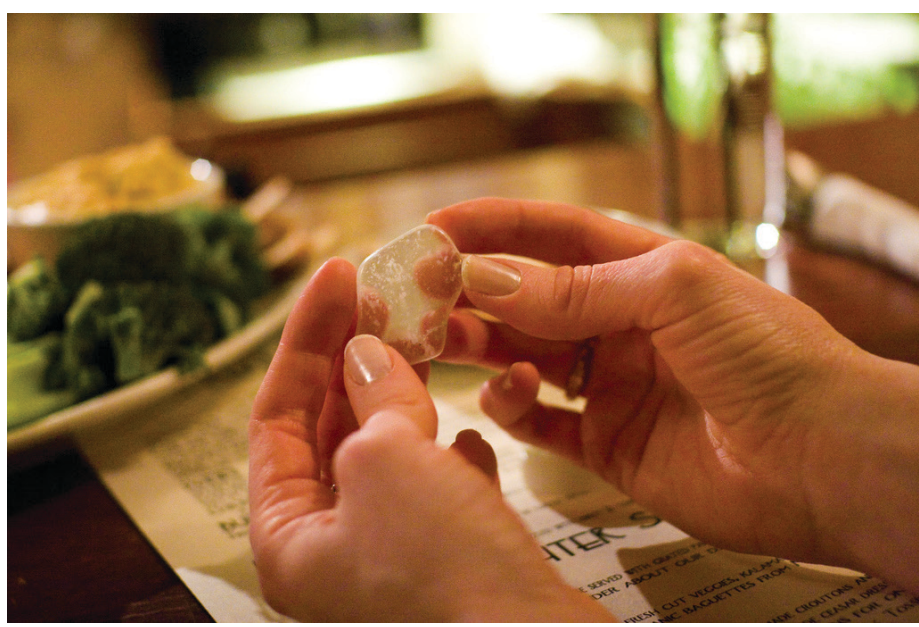

Figura 1. La tiamina se le llama también vitamina $B_{1}$ Credits: Jonathan Lidbeck CC BY 2.0 http://flic.kr/p/4CRUjc

1. The English version of this document is FCS8809/FY891 Facts About Minerals. Este documento FCS8809s, es uno de una serie del Departamento de Ciencias de la Familia, la Juventud y la Comunidad, Servicio de Extensión Cooperativa de la Florida, Instituto de Alimentos y Ciencias Agrícolas, Universidad de la Florida. Publicado noviembre de 2012. Visite el sitio web en EDIS http://edis.ifas.ufl.edu/.

2. R. Elaine Turner, PhD, RD, profesora y decano asociada, College of Agricultural and Life Sciences; Wendy J. Dahl, PhD, RD, profesora asistente, Food Science and Human Nutrition Department, Universidad de la Florida, Gainesville, FL 32611. 


\section{¿Cómo funcionan los minerales en el cuerpo?}

Los minerales trabajan de dos maneras en el cuerpo. Muchos minerales apoyan con el soporte de las células del cuerpo y la estructura. Por ejemplo, el calcio y el fósforo ayudan a formar los huesos, y el hierro es una parte esencial para las células rojas en la sangre.

Los minerales también trabajan para regular muchos procesos del cuerpo. El sodio y el potasio son importantes para la función del sistema nervioso. El cromo ayuda a normalizar los niveles de glucosa en la sangre. El mineral selenio trabaja con la vitamina E como antioxidante, ayudando a prevenir que las células se dañen por el oxígeno (1).

\section{¿Dónde encontramos los minerales en los alimentos?}

Todos los grupos alimenticios tienen alimentos ricos en minerales. Por ejemplo, la leche es una buena fuente de calcio, y la carne roja es rica en hierro y zinc. Las frutas y los vegetales son buenas fuentes de potasio. Los granos enteros son ricos en magnesio, selenio y cromo. Las nueces y las semillas son fuentes de cobre y manganeso.

Es importante comer una variedad de alimentos de cada grupo para obtener todos los minerales en su dieta.

\section{¿Los productos animales son mejor fuente de minerales que los alimentos provenientes de plantas?}

Algunos minerales (como el hierro y el zinc) tienden a ser mejor absorbidos por el cuerpo cuando son de origen animal que cuando son de origen vegetal. El fitato y el oxalato, los cuales son encontrados principalmente en granos enteros, vegetales y legumbres, reducen la absorción de algunos minerales (2). De todos modos, los alimentos de origen vegetal son importantes fuentes de muchos minerales, así que las dietas ricas en alimentos de plantas pueden proveer una gran variedad de cantidades de minerales adecuados.

\section{¿Procesar los alimentos afecta el contenido de minerales en los alimentos?}

Los minerales son estables en los alimentos. Generalmente se quedan en los alimentos hasta después de cocinarlos, enlatarlos, o congelarlos. Sin embargo, procesar los alimentos puede afectar el contenido de algunos minerales. Por ejemplo, refinar o moler disminuirá el contenido de cromo en los alimentos y los procesos que envuelven aditivos alimenticios pueden incrementar el contenido de fósforo en los alimentos (3).

Procesar también afecta el balance de sodio y potasio en los vegetales. Los vegetales frescos son ricos en potasio y naturalmente bajos en sodio. Los vegetales enlatados usualmente tienen un mayor contenido de sodio y sales agregadas.

\section{¿Cuánto de cada mineral necesito por día?}

La cantidad de minerales que necesitamos es muy pocamucho menor que la cantidad de carbohidratos, proteínas y grasas requeridas para una dieta saludable. La mayoría de los adultos necesitan alrededor de 1,000 miligramos de calcio al día, pero sólo 10 a 15 miligramos de hierro y zinc al día (4). La tabla 2 lista la dosis dietética recomendada (RDA) y el consumo adecuado (AI), el consumo diario que debe cumplir con las necesidades de la mayoría de personas saludables.

Necesitamos menos de 100 microgramos de cromo, selenio y molibdeno. ¡Para darle una idea de que tan poco esto es, una cucharadita de selenio podría satisfacer la necesidad diaria de más de 90,000 adultos!

El Valor Diario de un mineral en una etiqueta de un alimento le muestra el porcentaje de lo que un adulto saludable necesita de esa vitamina en un alimento. Por ejemplo, un vaso de leche baja en grasa de 8 onzas provee $30 \%$ del Valor Diario de calcio.

Tabla 2. Dosis Dietética Recomendada (RDA) o el Consumo Adecuado (Al) para algunos minerales seleccionados (4).

\begin{tabular}{|c|c|c|c|c|c|}
\hline & $\begin{array}{l}\text { Calcio } \\
\text { (mg/d) }\end{array}$ & $\begin{array}{c}\text { Fósforo } \\
\text { (mg/d) }\end{array}$ & $\begin{array}{c}\text { Magnesio } \\
(\mathrm{mg} / \mathrm{d})\end{array}$ & $\begin{array}{l}\text { Hierro } \\
\text { (mg/d) }\end{array}$ & $\begin{array}{c}\text { Zinc } \\
(\mathrm{mg} / \mathrm{d})\end{array}$ \\
\hline \multicolumn{6}{|l|}{ Hombres } \\
\hline $19-30 a$ & 1000 & 700 & 400 & 8 & 11 \\
\hline $31-70 a$ & 1000 & 700 & 420 & 8 & 11 \\
\hline $71+$ & 1200 & 700 & 420 & 8 & 11 \\
\hline \multicolumn{6}{|l|}{ Mujeres } \\
\hline $19-30 a$ & 1000 & 700 & 310 & 18 & 8 \\
\hline $31-50 a$ & 1000 & 700 & 320 & 18 & 8 \\
\hline $51+$ & 1200 & 700 & 320 & 8 & 8 \\
\hline \multicolumn{6}{|c|}{$\begin{array}{c}\mathrm{mg} / \mathrm{d}=\text { miligramos por día } \\
\quad \mathrm{a}=\text { anos }\end{array}$} \\
\hline
\end{tabular}




\section{¿Debería tomar suplementos para obtener los minerales que necesito?}

Es posible obtener todos los minerales que necesita al hacer decisiones saludables cuando compra alimentos de todos los grupos alimenticios en MiPlato/MyPlate (visite ChooseMyPlate.gov). Pero hay algunas situaciones en las que se necesitan los suplementos:

- A las mujeres en sus años prenatales se les puede dificultar conseguir todo el hierro que necesitan en los alimentos.

- Las personas alérgicas a la leche pueden tener dificultad obteniendo suficiente calcio.

- Las mujeres embarazadas deben preguntarle a sus doctores que suplementos son buenos para ellas.

- Algunas veces tomarse un suplemento como el hierro puede causar daños estomacales. Si esto ocurre, intente tomar el suplemento antes de dormir, o use un suplemento de dispersión lenta.

Tabla 3. Etiqueta típica de un suplemento de minerales.

\begin{tabular}{|c|c|}
\hline \multicolumn{2}{|c|}{ Datos del suplemento } \\
\hline \multicolumn{2}{|c|}{ Tamaño de la porción: 1 tableta } \\
\hline Cantidad por porción & $\%$ Valor Diario \\
\hline Calorías 10 & - \\
\hline Total Carbohidrato $2 \mathrm{~g}$ & $<1 \%$ \\
\hline Azucares $2 \mathrm{~g}$ & - \\
\hline Calcio 600mg & $60 \%$ \\
\hline Magnesio 40mg & $10 \%$ \\
\hline Zinc 7.5mg & $50 \%$ \\
\hline Cobre 1mg & $50 \%$ \\
\hline Manganeso 1.8mg & $90 \%$ \\
\hline Boro 250mcg & $*$ \\
\hline *Valor Diario no establecido \\
Porcentaje de Valor Diario basado en una dieta de 2,000 calorías. \\
\hline
\end{tabular}

\section{¿Puede altas cantidades de minerales ser perjudiciales?}

Con los minerales, como con muchas cosas en la vida, más no significa que es necesariamente mejor. Muchos minerales en grandes cantidades pueden ser tóxicos, con efectos secundarios desde estreñimiento hasta problemas en el hígado y daños en los riñones. Mucho sodio puede contribuir a la presión arterial alta en algunas personas.
Hay recomendación de consumo máximo de la mayoría de minerales. Generalmente el consumo excesivo de minerales viene de altas dosis de suplementos. Por eso muchas personas deben elegir consumir no más del nivel máximo tolerable (UL) de minerales cada día. El UL para algunos minerales se especifica en la tabla 4 .

Tabla 4. Nivel máximo de consumo tolerable (UL) para algunos minerales seleccionados.

\begin{tabular}{|c|c|c|c|c|c|}
\hline & $\begin{array}{c}\text { Calcio } \\
\text { (mg/d) }\end{array}$ & $\begin{array}{c}\text { Fósforo } \\
\text { (mg/d) }\end{array}$ & $\begin{array}{c}\text { Magnesio } \\
\text { (mg/d) }\end{array}$ & $\begin{array}{c}\text { Hierro } \\
\text { (mg/d) }\end{array}$ & $\begin{array}{c}\text { Zinc } \\
\text { (mg/d) }\end{array}$ \\
\hline UL & $2500^{*}$ & 4000 & 350 & 45 & 40 \\
\hline
\end{tabular}

*Para hombres y mujeres mayores de 50 anos, el UL de calcio es de $2000 \mathrm{mg} / \mathrm{d}$.

$\mathrm{mg} / \mathrm{d}=$ miligramos por día

Si usted esta tomando medicinas en este momento, debe consultar con su doctor o farmaceuta para saber si hay alguna razón por la cual no deba tomar suplementos de minerales. También para saber si debe ajustar las horas para tomar sus suplementos y otras medicinas.

Algunos suplementos pueden interferir que tan bien trabaja un medicamento en su cuerpo. También algunos medicamentos interfieren con que tan bien el cuerpo usa los minerales. Por esto es importante preguntarle a su doctor o farmaceuta antes de tomar suplementos de minerales.

\section{¿Dónde puedo obtener más información sobre minerales?}

¿Dónde puedo obtener más información sobre minerales?

El agente de Ciencias de la Familia y del Consumidor (FCS) en la oficina de extensión de su condado puede tener más información escrita y clases de nutrición para que usted asista. Además, un dietista registrado (RD) puede proporcionarle información confiable.

Más información nutricional confiable se puede encontrar en los siguientes sitios del Internet:

http://fycs.ifas.ufl.edu

http://solutionsforyourlife.ufl.edu

http://www.nutrition.gov

http://www.nal.usda.gov/fnic 


\section{Referencias}

1. Higdon, J. Micronutrient Research for Optimum Health. Linus Pauling Institute, Oregon State University, 2003

(Reviewed 2007). http://lpi.oregonstate.edu/infocenter/ minerals/chromium/

2. Gibson R, Bailey K, Gibbs M, Ferguson E. A review of phytate, iron, zinc, and calcium concentrations in plant-based complementary foods used in low-income countries and implications for bioavailability. Food Nutr Bull. 2010 Jun 31 (2 Suppl):S134-46.

3. Benini O, D'Alessandro C, Gianfaldoni D, Cupisti A. Extra-Phosphate Load from Food Additives in Commonly Eaten Foods: A Real and Insidious Danger for Renal Patients. J Ren Nutr. 2010 Nov 3. [Epub ahead of print]

4. Dietary Reference Intakes (DRIs): Recommended Intakes for Individuals. Food and Nutrition Board, Institute of Medicine, National Academies Press, 2004. http://www. iom.edu/Activities/Nutrition/SummaryDRIs/ /media/ Files/Activity\%20Files/Nutrition/DRIs/5_Summary\%20 Table\%20Tables\%201-4.pdf 